\title{
How We Do It: The Hickey Technique for Removing A Foreign Object from the Nasal Cavity of A Child
}

\author{
M Rashid ${ }^{1 *}$, J Brittain'2, E Massri² and S Hickey ${ }^{2}$ \\ ${ }^{1}$ Department of Otolaryngology; Head \& Neck Surgery, Bedfordshire Hospitals NHS Foundation Trust, UK \\ ${ }^{2}$ Department of Otolaryngology; Head \& Neck Surgery, South Devon NHS Trust, UK
}

*Corresponding author: M Rashid, Department of Otolaryngology; Head \& Neck Surgery, Bedfordshire Hospitals NHS Foundation Trust, UK.

Received Date: September 05, 2020

Published Date: October 15, 2020

Key Points

1) Removing foreign bodies from children is a common procedure.

2) Failure to do so due to an uncooperative child or technical difficulty leads to the risk, expense and inconvenience of a general anaesthetic.

3) The Hickey technique is a manoeuvre which allows maximal access and visibility to the nasal cavity even in an uncooperative child.

\section{Opinion}

The removal of foreign bodies from the nose is a common task for emergency departments and otolaryngologists. It is most common in children and those with learning difficulties [1,2]. Intranasal foreign bodies are often benign but can cause nasal obstruction and irritation if not treated. Certain objects, such as button batteries and paired batteries, are locally destructive [3]. Management of foreign bodies generally starts with non-invasive methods such as positive pressure techniques, through instrumental removal and finally as a last resort to removal under a general anaesthetic [1,3]. Because of the cost and increased risk associated with a latter, there is a clear benefit to removing objects without recourse to theatre; but this can be difficult if the patient is an uncooperative child.

This article will describe a method of positioning a child which allows clear visualization of the nasal cavity, good access for instrumentation and perhaps most importantly excellent stabilization of the patient's head. The potential benefits of the technique are demonstrated by the senior author of this article, who in 20 years of consultant practice in otolaryngology has not been required to take a child to theatre for removal of an intranasal foreign body.

The technique: an approach to removing an intranasal foreign body.

Step 1: Review the patient in a well-lit and quiet environment with the parent or a trusted adult present. Attempt to ascertain the identity of the foreign body. Build a rapport with the child and parent as much as possible and talk them through what you are doing to gain their trust.

Step 2: Position the child in the parent's lap facing the parent. The practitioner should sit facing opposite the parent so that they are face to face with the child between them sitting on the parent's knees (Figure 1).

Step 3: The parent should then gently lower the child backwards towards the practitioner so that the child's head is resting on the practitioner's lap (Figure 2). 


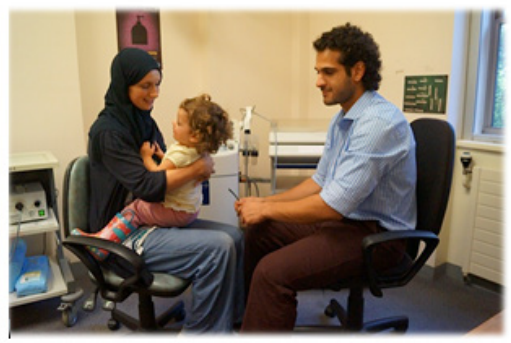

Figure 1

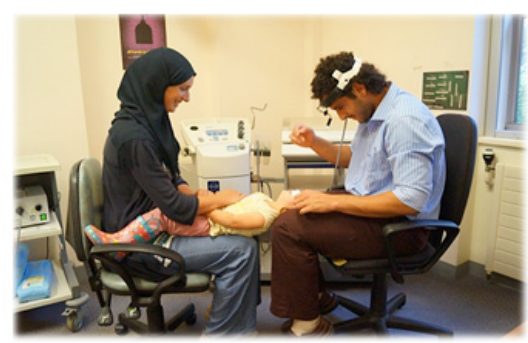

Figure 2

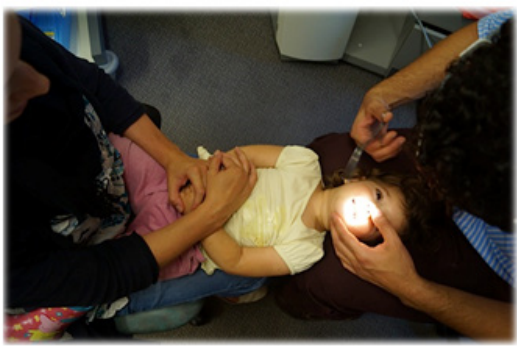

Figure 3

Step 4: With the child in this position the parent can hold their arms while the practitioner gently holds and stabilizes the child's head between their legs (Figure 3).

Step 5: The practitioner then can gently expose the nasal cavity with one hand by pushing the tip of the nose up.

Step 6: With a head light and an appropriate instrument such as a eustachian tube catheter the practitioner can then remove the foreign body.

\section{Discussion}

For many children instrumentation is the only effective technique for removing an intranasal foreign body [1]. While evidence for the efficacy of the technique is anecdotal, in the senior author's experience of 20 years of using it no child has required general anaesthesia to remove a foreign body from the nasal space.

It has been suggested to the author that the supine position of the child in this manoeuvre presents a risk of aspiration should the foreign body be pushed inadvertently into the postnasal space. While in the authors' opinion the gag and cough reflex of a child conspire to make this unlikely it may be a consideration, particularly in the case of a very distressed and uncooperative child.

There are many techniques for the removal of intranasal foreign bodies [1-4] and perhaps the most important factor in the choice of technique is practitioner preference. At the very least the above technique provides another avenue to be tried before resorting to a general anaesthetic. A technique which reduces the overall number of general anaesthetics required for children is beneficial to institutions, practitioners and patients.

\section{Acknowledgement}

None.

\section{Conflict of Interest}

None.

\section{References}

1. Kadish HA, Corneli HM (1997) Removal of nasal foreign bodies in the pediatric population. Am J Emerg Med 15(1): 54-57.

2. Kiger J, Brenkert T, Losek J (2008) Nasal Foreign Body Removal in Children. Pediatr Emerg Care 28(11): 785-792.

3. Kiger, Brenkert Te, Losek Jd (2008) Nasal Foreign Body Removal in Children. Pediatric Emergency Care 24(11).

4. Purohit N, Ray S, Wilson T, O P Chawla (2008) The 'parent's kiss': an effective way to remove paediatric nasal foreign bodies. Ann R Coll Surg Engl 90: 420-422. 